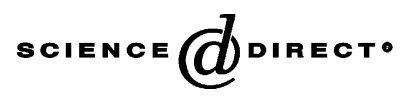

Acta Tropica 94 (2005) 55-59

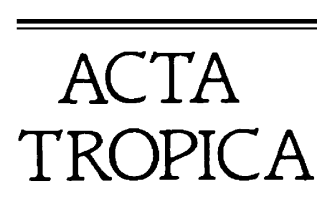

www.elsevier.com/locate/actatropica

\title{
Polymerase chain reaction (PCR) is highly sensitive for diagnosis of mucosal leishmaniasis
}

\author{
Jene Greyce S. Oliveira ${ }^{\mathrm{a}}$, Fernanda O. Novais ${ }^{\mathrm{b}}$, Camila I. de Oliveira ${ }^{\mathrm{b}}$, \\ Antonio C. da Cruz Junior ${ }^{\mathrm{a}}$, Léon Fábio Campos ${ }^{\mathrm{a}}$, Any V. da Rocha ${ }^{\mathrm{a}}$, \\ Viviane Boaventura $^{\mathrm{b}}$, Almério Noronha ${ }^{\mathrm{b}}$, Jackson M.L. Costa ${ }^{\mathrm{b}}$, Aldina Barral ${ }^{\mathrm{b}, \mathrm{c}, *}$ \\ ${ }^{a}$ Fundação Hospital do Acre, Rodovia BR364, km 2, Distrito Industrial, Rio Branco, AC 69914-220, Brazil \\ ${ }^{\mathrm{b}}$ Centro de Pesquisas Gonçalo Muniz, Fundação Oswaldo Cruz, Rua Waldemar Falcão, Av. Waldemar Falcão, \\ 121 Brotas, CEP 40295-001, Salvador, BA, Brazil \\ ${ }^{\mathrm{c}}$ Faculdade de Medicina da Bahia, Universidade Federal da Bahia, Praça XV de Novembro, s/n Largo do Terreiro de Jeusus, \\ Salvador, BA 40025-010, Brazil
}

Received 1 June 2004; received in revised form 4 October 2004; accepted 16 December 2004

Available online 11 March 2005

\begin{abstract}
We evaluated the use of polymerase chain reaction (PCR) for diagnosis of mucosal leishmaniasis (ML) in an endemic area in Acre, Brazil, where Leishmania braziliensis is present. Leishmania DNA was detected 34 of 35 cases, yielding a positivity rate of $97.1 \%$, which was higher than the positivity rates for all of the other diagnostic methods studied, namely Montenegro skin test (MST), anti-Leishmania serological testing and microscopic examination of lesion biopsy specimens. These findings have led us to propose guidelines for the diagnosis of ML that use PCR as the principal method of parasitological confirmation of cases.
\end{abstract}

(C) 2005 Elsevier B.V. All rights reserved.

Keywords: Polymerase chain reaction; Leishmania braziliensis; Mucosal leishmaniasis

\section{Introduction}

Leishmania is a protozoan parasite and the causative agent of leishmaniasis, a human disease with diverse clinical manifestations. An estimated 12 million peo-

\footnotetext{
* Corresponding author. Tel.: +55 $713568782 \times 215$; fax: $+55713568782 \times 261$.

E-mail address: abarral@cpqgm.fiocruz.br (A. Barral).
}

ple are currently infected with Leishmania species and 350 million people currently live at risk of infection (http://www.who.int/tdr/dw/leish2004.htm). American cutaneous leishmaniasis (ACL) is characterized by a cutaneous ulcer with elevated borders and a sharp crater, which, when caused by parasites of the Leishmania braziliensis complex, may spontaneously heal, disseminate to the skin or metastasize to the nasopharyngeal tract. This last manifestation, known as 
mucosal leishmaniasis (ML), occurs in $2-4 \%$ of patients with ACL. In this case, the lesions are chronic and spontaneous healing is rarely observed (Marsden, 1994). The number of ML cases has increased in the last few years in Northern Brazil, particularly in the state of Acre, where it accounts for $21 \%$ of the ACL cases (FUNASA, 2000).

Definitive diagnosis of leishmaniasis is made by the demonstration of Leishmania parasites in patients' tissue sample or by culture or, still, by inoculation of animals with material extracted from lesions. These methods are time consuming, laborious, and generally, require experienced personnel and special facilities in order to be performed. However, due to the paucity of parasites in lesions, these methods usually present low sensitivities. To overcome these obstacles, several methods based on the amplification of Leishmania DNA from patients' tissues have been developed (Belli et al., 1998; Aviles et al., 1999; Rodrigues et al., 2002; Weigle et al., 2002). These studies have collectively shown that polymerase chain reaction (PCR) sensitivity for Leishmania detection in biopsy samples ranges from 75.7 to $100 \%$ whereas specificity ranges from 96.4 to $100 \%$. In terms of ML, reports in the literature have shown that the sensitivity of detection by PCR varied from 47.4 to $83.3 \%$ (Uezato et al., 1998; Piñero et al., 1999; Onuma et al., 2001). The detection of parasite DNA is sufficient for diagnosis purposes, however, higher specificity, such as identification of parasite species can contribute directly to the understanding of the epidemiology of leishmaniasis.

Several research groups have examined the use of the PCR as a diagnostic tool in areas where leishmaniasis is endemic, however, to this date diagnosis is still largely based on immunological tests such as serology and/or Montenegro skin test (MST). The aim of the present study was to evaluate the contribution of the PCR to the diagnosis of ML in an endemic area in Brazil.

\section{Subjects, materials and methods}

\subsection{Study area and patients}

Biopsy specimens were obtained from patients with ML who attended the otorhinolaryngology clinic of
Table 1

Clinical epidemiological characteristics of 35 patients with mucosal leishmaniasis enrolled in a study of diagnosis of Leishmania by PCR

\begin{tabular}{ll}
\hline Characteristic or finding & Value \\
\hline Male sex & $28(80 \%)$ \\
Age, years (median) & $39(6-80)$ \\
Occurrence of previous infection & $33(94.3 \%)$ \\
Presence of cutaneous scar & $33(94.3 \%)$ \\
Duration of disease, days (me- & $35(1-60)$ \\
$\quad$ dian) & \\
Dose of intravenous pentavalent & $90(20-180)$ \\
$\quad$ antimony, ampoules (median) & \\
Positive Montenegro skin test & $33(94.3 \%)$ \\
\hline
\end{tabular}

the Hospital Foundation of the State of Acre (FUNDAHCRE) and the Barral y Barral Health Care Centre during the period from 1999 to 2002. These health posts are located in Rio Branco, Acre, Northern Brazil, where L. braziliensis is endemic. Research was conducted in accordance with the Research Ethics Committee from the State Foundation Hospital of Acre guidelines for Human Experimentation and the Brazilian Ministry of Health regulations for research involving humans. Informed consent was obtained from all individuals enrolled in the study. All patients underwent a complete physical examination, as well as clinical and laboratory evaluations. Patients were submitted to an anterior rhinoscopy and oral examination and, in some cases, patients were also submitted to endoscopic exploration with an optical fibroscope $\left(0^{\circ}\right.$ or $70^{\circ}$ telescope), in order to probe for extension of the lesion to the pharynx or larynx. Mucosal lesions were characterized by diffuse infiltration with a granular surface or ulceration. The clinical characteristics of the 35 patients with ML, enrolled in this study are shown in Tables 1 and 2. All patients were treated with intravenous pentavalent antimony (Glucantime $^{\circledR}$ ) at a dose of $20 \mathrm{mg} \mathrm{Sb}^{5+}(\mathrm{kg} \text { day })^{-1}$ for 30 days. All patients were cured, as show by the presence of healed mucosal lesion, disappearance of inflammatory signs and the presence of a scar, without recurrences up to 1 year after treatment. The definition of a confirmed case of ML was, in this case, based on the presence of a compatible epidemiological history, the presence of circulating antibodies (as detected by immunofluorescense assay, IFA) or a positive Montenegro skin test and clinical response to treatment. 
Table 2

Clinical presentation of mucosal lesions in mucosal leishmaniasis patients enrolled in a study of diagnosis of Leishmania by PCR

\begin{tabular}{lc}
\hline Characteristic or finding & Value $^{\mathrm{a}}$ \\
\hline Site & \\
Nose & $28(80)$ \\
Nose and oropharynx & $7(20)$ \\
Type $^{\mathrm{b}}$ & \\
Infiltrative/vegetating-ulcer $_{\text {Mutilate/destroyed-ulcer }}$ & $15(42.9)$ \\
Dry atrophic & $7(20)$ \\
Associated types & $6(17.1)$ \\
Dry ulcer & $4(11.4)$ \\
Polypus & $2(5.7)$ \\
\hline
\end{tabular}

a Data are no. of patients (\%).

${ }^{\mathrm{b}}$ Classification proposed by Ribeiro and Lopes-Filho (1994).

\subsection{MST and serological testing}

The Montenegro skin test, in which a delayed-type hypersensitivity reaction is provoked, was performed with a soluble Leishmania antigen and it was prepared as described elsewhere (Reed et al., 1986). Leishmania parasites were used to perform an indirect immunofluorescense assay test to detect the presence of antiLeishmania antibodies, as described elsewhere (Cuba Cuba et al., 1980).

\subsection{Sample collection}

After the administration of a local anesthetic, biopsy samples were obtained from the lesions using forceps or Takahachi tweezers. Biopsy tissue speciments were fixed in $10 \%$ buffered formalin $(\mathrm{pH} \mathrm{7.0)}$ and were processed using standard techniques for paraffin embedding. Tissue sections were stained with hematoxylin-eosin (HE) and immunohistochemical analysis was performed using a polyclonal antibody against Leishmania, as described elsewhere (Barral et al., 1991). For negative controls, biopsy specimens were obtained from a collection of lesions originated from mucosal diseases not related to leishmaniasis.

\subsection{Polymerase chain reaction}

Thirty-micrometer sections of the paraffin blocks containing patients' biopsy specimens were used for
DNA extraction. DNA extraction and purification were performed using the Nucleon HT kit (GE Healthcare), in accordance with the manufacturer's instructions. Samples were eluted in $50 \mu \mathrm{l}$ of TE $(10 \mathrm{mmol} / 1 \mathrm{Tris}-\mathrm{HCl}[\mathrm{pH} 8.0]$ and $0.1 \mathrm{mmol} / \mathrm{l}$ EDTA $[\mathrm{pH}, 8.0]$. PCR was performed with primers $5^{\prime}$-GGG(G/T)AGGGGCGTTCT(G/C)CGAA-3' and $5^{\prime}-(\mathrm{G} /$ C)(G/C)(G/C)(A/T)CTAT(A/T)TTACACCAACCCC3 , which target the amplification of the 120-bp conserved region of the Leishmania kDNA minicircle of all Leishmania species. A reaction mixture was prepared containing $50 \mathrm{mmol} / \mathrm{K} \mathrm{KCl}, 10 \mathrm{mmol}$ Tris- $\mathrm{HCl}$ ( $\mathrm{pH} 8.0$ ), $0.2 \mathrm{mmol} / \mathrm{l}$ each deoxyribonucleotide (Invitrogen), $1 \mu \mathrm{mol} / \mathrm{l}$ each primer, 1.25 units of Taq polymerase (Invitrogen) and $2.5 \mu \mathrm{l}$ of DNA sample in a final volume of $25 \mu \mathrm{l}$. The PCR conditions were as follows: denaturation at $94^{\circ} \mathrm{C}$ for $3 \mathrm{~min}$, followed by 30 cycles of $94^{\circ} \mathrm{C}$ for $30 \mathrm{~s}, 55^{\circ} \mathrm{C}$ for $30 \mathrm{~s}$ and $94{ }^{\circ} \mathrm{C}$ for $45 \mathrm{~s}$ with a final extension of $72^{\circ} \mathrm{C}$ for $10 \mathrm{~min}$. The amplification reactions were analyzed by agarose gel electrophoresis, followed by ethidium bromide staining and visualization under UV light. DNA from the reference L. braziliensis strain MHOM/BR/75/2904 was used as a positive control.

\section{Results}

\subsection{Clinical characteristics of patients with $M L$}

Biopsy samples were obtained from 35 patients with ML, all of whom were clinically cured after completion of the treatment regimen. Tables 1 and 2 show the clinical characteristics of this patient population. The MST was positive for 33 (94.3\%) of 35 patients and negative for $2(5.7 \%)$ of 35 patients. The lesion involved nose and oropharynx in $7(20 \%)$ of 35 patients and $22(63 \%)$ of 35 patients developed destructive or vegetating ulcers.

\subsection{Conventional methods for detection of Leishmania}

Table 3 shows the results obtained by conventional diagnostic methods of Leishmania. The 35-biopsy samples were submitted to histopathological examination, which consisted of both HE staining and immunohistochemical testing of biopsy sections. Direct visual- 
Table 3

Results of tests used for diagnosis of mucosal leishmaniasis

\begin{tabular}{ll}
\hline Method $^{\text {a }}$ & $\begin{array}{l}\text { No. of positive } \\
\text { results/total no. of } \\
\text { tests performed }(\%)\end{array}$ \\
\hline HE & $20 / 35(57)$ \\
IHQ & $24 / 35(68.6)$ \\
PCR & $34 / 35(97)$ \\
\hline
\end{tabular}

${ }^{\text {a }}$ HE: hematoxylin-eosin staining, IHQ: immunohistochemistry.

ization of parasites by HE staining was possible in 20 $(57 \%)$ of 35 samples whereas immuohistochemistry allowed for the detection of parasites in 24 (68.6\%) of 35 samples. Anti-Leishmania serological testing was performed in 12 samples and the sensitivity was $83.3 \%$ (data not shown).

\subsection{PCR detection of Leishmania}

PCR was performed using primers that amplify a conserved region of Leishmania kinetoplast minicircles. In 34 (97.1\%) of 35 biopsy samples examined, the characteristic 120-bp amplicon was detected (Fig. 1). Positive and negative controls were included in all reactions to ensure correct amplification of the Leishmania product. The specificity of the PCR for the detection of Leishmania species was found to be $100 \%$ since no amplification product was detected in samples from patients with ulcers not related to leishmaniasis or biopsy samples from normal skin (data not shown). The sensitivity of the PCR was significantly higher (0.0001) when compared to MST.

\section{Discussion}

In the present study, we have investigated the benefits of the PCR as a diagnostic tool for ML, in patients' biopsy samples. In terms of clinical utility, the PCR offers several advantages such as high sensitivity and

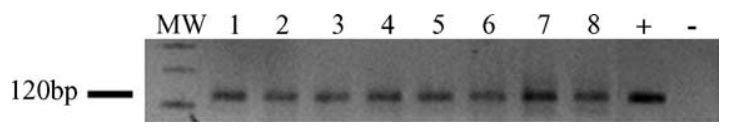

Fig. 1. PCR amplification of Leishmania in biopsy samples obtained from patients with mucosal leishmaniasis (ML). MW, 100-bp DNA ladder DNA size marker, lanes (1-8) biopsy specimens obtained from patients with ML; (+) positive control, $(-)$ negative control. specificity. Most importantly, however, PCR is more rapid than currently available immunological (serology and Montenegro skin test) and parasitological methods (microscopic examination of lesion biopsy by HE or immunostaining) (de Bruijn and Barker, 1992; Rodgers et al., 1990; Pirmez et al., 1999; Rodrigues et al., 2002; Romero et al., 2001; Isaza et al., 2002). PCR has also been used for diagnosis of mucosal leishmaniasis in blood sample (Piñero et al., 1999).

Our results show that the PCR was positive in 34 of 35 biopsy samples obtained from patients with ML, regardless of the results obtained with other diagnostic procedures; therefore, positivity, in this case, was $97.1 \%$. This positivity rate was calculated based on the fact that all patients in this study showed clinical cure, as shown by total scarring of the initial lesion. As previously reported, although clinical cure cannot be considered as "gold standard" for the diagnosis of ML or even cutaneous leishmaniasis, it is a strong indicator that the patient was infected with Leishmania parasites (de Oliveira et al., 2003). Moreover, patients enrolled in this study presented a compatible epidemiological history as evidenced by the presence of either lesion in mucosal areas, previous infection by Leishmania, positive serologic test and/or positive Montenegro skin test. The PCR was $100 \%$ specific since no amplification product was obtained in biopsies from dermatological lesions not caused by Leishmania or biopsies obtained from normal skin (data not shown). Parasitological confirmation by histopathology was possible in $57 \%$ of samples and this rate of positivity was increased to $68.6 \%$ when immunohistochemistry was used. This is compatible with previously published results (Belli et al., 1998; Rodrigues et al., 2002).

The Montenegro skin test is simple and sensitive and it is the main test used for confirmation of infection by Leishmania, especially in rural areas where resources for laboratory diagnosis are scarce or nonexistent (Aviles et al., 1999). In this study, we used a soluble Leishmania antigen (Reed et al., 1986) and we obtained a positive result in $94.3 \%$ of patients, similar to previously published reports (Passos et al., 2002). However, this test cannot discriminate between past and present infection, since we have observed that patients with cutaneous scar, indicative of Leishmania infection in the past, have positive skin reaction to Leishmania antigen. 
In conclusion, the present data support the view that the PCR is the best alternative for diagnosis of ML, when compared to conventional parasitological and immunological methods. To our knowledge, this is the first report on the diagnosis of ML by PCR in an endemic area in Brazil. Despite the still elevated costs associated with molecular diagnosis, the continuous simplification of collection procedures and sample processing associated with the high sensitivity and specificity indicate that the PCR will indeed be the method of choice for the diagnosis of leishmaniasis, particularly ML, where a fatal outcome may occur.

\section{Acknowledgments}

This work was supported by PAPES/FIOCRUZ and CNPq. A.B. is Senior Fellow of the Brazilian Agency for Research $(\mathrm{CNPq})$. We thank Vera Vinhas for technical assistance with immunohistochemistry and Manoel Barral-Netto for critical reviewing of the manuscript.

\section{References}

Aviles, H., Belli, A., Armijos, R., Armijos, R., Monoroy, F.P., Harris, E., 1999. PCR detection and identification of Leishmania parasites in clinical specimens in Ecuador: a comparison with classical diagnostic methods. J. Parasitol. 85, 181-187.

Barral, A., Pedral-Sampaio, D., Grimaldi Junior, G., Momem, H., McMahon-Pratt, D., Jesus, A.R., Almeida, R., Badaró, R., BarralNetto, M., Carvalho, E.M., Johnson, W.D., 1991. Leishmaniasis in Bahia, Brazil: evidence that Leishmania amazonensis produces a wide spectrum of clinical disease. Am. J. Trop. Med. Hyg. 44, 536-546.

Belli, A., Rodriguez, B., Aviles, H., Harris, E., 1998. Simplified polymerase chain reaction detection of new world Leishmania in clinical specimens of cutaneous leishmaniasis. Am. J. Trop. Med. Hyg. 58, 102-109.

Cuba Cuba, C.A., Marsden, P.D., Barreto, A.C., Rocha, R., Sampaio, R.P., Patzlaff, L., 1980. Parasitologic and immunologic diagnosis of American cutaneous leishmaniasis. Bol. Oficina Sanit. Panam. 89, 195-208.

de Bruijn, M.H., Barker, D.C., 1992. Diagnosis of New World leishmaniasis: specific detection of species of the Leishmania braziliensis complex by amplification of kinetoplast DNA. Acta Trop. 52, 45-58.

de Oliveira, C.I., Báfica, A., Oliveira, F., Favali, C.B.F., Correa, T., Freitas, L.A.R., Nascimento, E., Costa, J.M.L., Barral, A., 2003. Clinical utility of polymerase chain reaction-based detection of Leishmania in the diagnosis of American cutaneous leishmaniasis. Clin. Infect. Dis. 37, 149-153.
FUNASA —Fundação Nacional de Saúde; 2000. Manual de Controle da Leishmaniose Tegumentar Americana, Brasília, Brazil, pp. 62.

Isaza, D.M., Arboleda, M., Restrepo, M., McCann, S.H., Barker, D.C., 2002. Validation of the polymerase chain reaction for the diagnosis of human cutaneous leishmaniasis in north-west Colombia. Trans. R. Soc. Trop. Med. Hyg. 96, S165-S168.

Marsden, P.D., 1994. Mucosal leishmaniasis due to Leishmania (Viannia) braziliensis $L(V) b$ in Três Braços, Bahia, Brazil. Rev. Soc. Bras. Med. Trop. 27, 93-101.

Onuma, H., Matsui, C., Inou, K., Uezato, H., Nonaka, S., Hashiguchi, Y., Morohashi, M., 2001. A case of mucosal leishmaniasis: benefical usage of polymerase chain reaction for diagnosis. Int. J. Dermatol. 40, 765-767.

Passos, V.M.A., Barreto, S.M., Romanha, A.J., Krettli, A.U., Volpini, A.C., Gontijo, C.M.F., Falcão, A.L., Lima-Costa, M.F.F., 2002. Leishmaniose tegumentar na região metropolitana de Belo Horizonte: aspectos clínicos, laboratoriais, terapêuticos e evolutivos (1985-1995). Rev. Soc. Bras. Med. Trop. 34, 5-12.

Piñero, J., Martínez, E., Pacheco, R., Aragón, Z., De Armas, F., Del Castilo, A., Valladares, B., 1999. PCR-ELISA for diagnosis of mucocutaneous leishmaniasis. Acta Trop. 73, 21-29.

Pirmez, C., da Silva Trajano, V., Paes-Oliveira Neto, M., Da Cruz, A.M., Gonçalves-da-Costa, S.C., Castanho, M., Degrave, W., Fernandes, O., 1999. Use of PCR in diagnosis of human american tegumentary leishmaniasis in Rio de Janeiro, Brazil. J. Clin. Microbiol. 37, 1819-1823.

Reed, S.G., Badaró, R., Masur, H., Carvalho, E.M., Lorenço, R., Lisboa, A., Teixeira, R., Johnson, W.D., Jones, T.C., 1986. Selection of a skin test antigen for American visceral leishmaniasis. Am. J. Trop. Med. Hyg. 35, 79-85.

Ribeiro FAQ, Lopes-Filho O. 1994. Doenças ÚlceroGranulomatosas em Otorrinolaringologia. Rocca, São Paulo, SP, pp.71-75.

Rodgers, M.R., Popper, S.J., Wirth, D.F., 1990. Amplification of kinetoplast DNA as a tool in the detection and diagnosis of Leishmania. Exp. Parasitol. 71, 267-275.

Rodrigues, E.H.G., Felinto de Brito, M.E., Mendonça, M.G., Werkhauser, R.P., Coutinho, E.M., Souza, W.V., Militao de Albuquerque, M.D.E.F., Jardim, M.L., Abath, F.G., 2002. Evaluation of PCR for diagnosis of American cutaneous leishmaniasis in an area of endemicity in northeastern Brazil. J. Clin. Microbiol. 40, 3572-3576.

Romero, G.A., Guerra, M.V., Paes, M.G., Cupolillo, E., Bentin Toaldo, C., Macedo, V.O., Fernandes, O., 2001. Sensitivity of the polymerase chain reaction for the diagnosis of cutaneous leishmaniasis due to Leishmania (Viannia) guyanensis. Acta Trop. 79, 225-229.

Uezato, H., Hagiwara, K., Hosokawa, A., Maruno, M., Nonaka, S., Oshiro, M., Nakashima, Y., Furuya, M., Hashiguchi, Y., 1998. Comparative studies of the detection rates of Leishmania parasites from formalin, ethanol-fixed, frozen human skin specimens by polymerase chain reaction and Southern blotting. J. Dermatol. 25, 623-631.

Weigle, K.A., Labrada, L.A., Lozano, C., Santrich, C., Barrer, D.C., 2002. PCR-based diagnosis of acute and chronic cutaneous Leishmaniasis caused by Leishmania (Viannia). J. Clin. Microbiol. 40, 601-606. 